\title{
Lessons from the field
}

\section{Transforming health professionals' education in Rwanda - Contributions from Social and Community Medicine}

\author{
Vincent Kalumire Cubaka ${ }^{1,2^{*}}$, Patrick Kyamanywa ${ }^{1}$, Maaike Flinkenflögel ${ }^{1,3}$, Michael Schriver ${ }^{1,2}$, \\ Emmanuel Ngabire ${ }^{1,3}$, Phil Cotton ${ }^{1}$ \\ ${ }^{1}$ College of Medicine and Health Sciences, University of Rwanda, Rwanda \\ ${ }^{2}$ Center for global health, Department of Public Health, Aarbus University, Denmark. \\ ${ }^{3}$ Inshuti Mu Buzima/Partners In Health, Rwanda
}

\begin{abstract}
Health professionals' education is undergoing enormous transformation internationally and also in Rwanda. We present the contribution of a Social and Community Medicine program at the University of Rwanda to this new era of community oriented, people centred and socially accountable health professionals' education.
\end{abstract}

Key words: Health Professionals’ Education, Undergraduate Medical Education, Primary Health Care, Social Medicine, Community Medicine, Curriculum Review, Rwanda

\section{Background}

Internationally, there is a movement to transform health professionals' education to prepare a health workforce that strengthens the health system by responding to the actual needs of the community, known as social accountability (WHO, 1995). Accordingly, the health system must put the population at the centre of care, and apply a holistic approach to service provision, recognising the patient as a biological, psychological and social being with health problems intricately placed in this context.

In 2013, the public health professionals' education system in Rwanda underwent a tremendous transformation process to gather all health professions educations (Nursing, Medicine, Public Health, Dentistry, Pharmacy etc) under one joint College of Medicine and Health Sciences in the newly formed sole national public university - the University of Rwanda. The move brought a unique opportunity to rethink the approach to educating fit-forpractice health professionals, as well as bringing health profession students together early in training.

Primary health care is the backbone of the Rwandan health system. In 2011, health centres managed around 15 times more outpatient visits than hospitals (National institute of statistics of Rwanda, 2014). Together with a 45,000 strong community health workforce, this frontline tier manages most common health problems, as well as delivers preventive care and health education to the pop- ulation. It is the foundation on which the entire health system rests, and all health professionals should understand and be able to respond to the health needs of the population at that primary care level, close to patients and their community. Dedicated health professionals' education curricula based on primary health care principles to foster social and community medicine values and attitudes early on and throughout training are thus a necessity (Mullan et al., 2011).

\section{Movements for transforming medical education}

In 1910, the Flexner Report caused a revolution in the American medical training by placing science and proper training facilities at the core of medical education. In the wake of Flexner, medical schools had to reinvent their structure and approaches using the biomedical model as the gold standard of training, and many schools had to close (Duffy, 2011).

A century later a new movement was launched with a ground-breaking paper on health professions' education known as the Frenk Report (Frenk et al., 2011). It described the need for a renewed, transformative learning strategy to develop leaders at all health system levels able to act as change agents for improvement, and provide population-centred care as part of a local and global health team. This overarching objective reinforces existing aims of learning to ensure the acquisition of knowledge and skills, as well as instilling appropriate pro-

*Corresponding author: cukalvin@icloud.com 
fessional values and preparing students for future challenges. The East African Health Professions Association is one of many advocates for the Frenk Report (Report from the inaugural meeting of the Eastern African Health Professionals Educators' Association, EAHPEA, 2013).

Another response to the centenary of the Flexner report was the launch of an international Delphi process with 130 organizations and individuals providing directions to make medical schools more socially accountable to improve quality, equity, relevance and effectiveness in health care (Boelen, 2011). It emphasises the importance of identifying the actual health needs in society and reorienting education accordingly, including redefining the roles of health professionals. A major recommendation was around building and strengthening of partnerships with all stakeholders in health care, including patients.

Furthermore, the Sub-Saharan African Medical School Study (SAMSS) emphasised the importance of engaging in international, regional and national partnerships, as well as developing multi-disciplinary, team-based education that is community-oriented (Mullan et al., 2011).

These recommendations move health professionals' education from an isolated learning phenomenon facilitated by educators in a classroom or health facility, to being a broader and more interactive process in which society and communities play a key role.

\section{Teaching and Learning Strategies in iSOCO}

Health professional educators in Rwanda are joining forces in the attempt to ensure a coherent and accountable education of the future workforce. One component of this process is the development of a Social and Community Medicine training program (iSOCO), from which there are lessons worth sharing.

The School of Medicine and Pharmacy, while undertaking a review of the medical curriculum, in 2014 developed this training program in recognition of a need to begin early in training community-oriented, socially-driven and team-based health professionals with a holistic and patient-centred approach. This curriculum development process was an example of interdisciplinary work involving educators from pharmacy, dentistry, public health and primary health care who put together knowledge, skills and experiences to develop a comprehensive yet fit-for-purpose curriculum.

The iSOCO training program was delivered by the Discipline of Primary Health Care and was developed as an integrated program in the revised 5-year medical degree that started in the academic year 2014-2015. Each year covers specific key elements under five main domains: public health; health systems; social medicine; communication; and professionalism, with the overall aim to graduate the 'desired Rwandan health care provider', who is a patient-centred and community-oriented care provider with the roles of communicator, collaborator, manager, health advocate, scholar and professional. Each year builds on the elements covered in the previous year(s) in an interactive way, using the flipped classroom model (Mclaughlin et al., 2014), e-learning platform, Moodle, and other learning approaches.

The flipped classroom model uses structured self-directed learning that takes place at home as preparation for classroom sessions, that only minimally use traditional lectures but rather involve discussion of main principles and contextual cases.

The Discipline of Primary Health Care uses the opensource e-learning platform Moodle to exploit innovative and modern e-methods for course preparation, reflection and feedback, aiming to enhance the quality of the teaching and learning experience(Al-Ajlan \& Zedan, 2008). All students can access videos, presentations, articles, books and other teaching materials as guidance for their self-directed learning and assignments. The website also serves as an exchange platform for discussion between teachers and students, and for assessments.

\section{Conclusion}

The College of Medicine and Health Sciences, University of Rwanda, is moving forward, becoming more socially accountable, providing teaching based on the needs of the Rwandan community and creating a learning environment that is favourable of the needs of the large number of students. It is important that all faculties and departments share their ideas and approaches to teaching in order to build a strong, coherent training program for our health professional students. The impact of this new curriculum is yet to be known, and sound evaluation and research methods should be applied to continuously assess the quality of educational strategies.

Creating awareness among health professional students of the social determinants that influence health and disease is vital from early in their training. This would help the college to deliver the desired Rwandan health care providers, who work as professionals with patients, communities and colleagues to improve the standards of care and life of Rwandans. 


\section{Competing interests: none}

\section{References}

Al-Ajlan, A., \& Zedan, H. (2008). Why Moodle. 2008 12th IEEE International Workshop on Future Trends of Distributed Computing Systems, 58-64. doi:10.1109/FTDCS.2008.22

Boelen, C. (2011). Global consensus on social accountability of medical schools. Santé publique (Vandoeuvre-lès-Nancy, France), 23(3), 247.

Duffy, T. P. (2011). The Flexner Report--100 years later. The Yale Journal of Biology and Medicine, 84(3), 269-76.

Frenk, J., Chen, L., Bhutta, Z. A., Cohen, J., Evans, T., Fineberg, H., Zurayk, H. (2011). Health Professionals for a New Century: Transforming Education to Strengthen Health Systems in an Interdependent World. The Lancet, 376(9756), 1923-1958. doi:10.1016/S0140-6736(10)61854-5

Mclaughlin, J. E., Roth, M. T., Glatt, D. M., Gharkholonarehe, N., Davidson, C. A., Griffin, L. M., Mumper, R. J. (2014). The Flipped Classroom: A Course Redesign to Foster Learning and Engagement in a Health Professions School, 89(2), 236-243. doi:10.1097/ACM.0000000000000086
Mullan, F., Frehywot, S., Omaswa, F., Buch, E., Chen, C., Greysen, S. R., Neusy, A.-J. (2011). Medical schools in subSaharan Africa. Lancet, 377(9771), 1113-1121. doi:10.1016/ S0140-6736(10)61961-7

National institute of statistics of Rwanda. (2014). Statistical Year Book 2014.

Report from the inaugural meeting of the Eastern African Health Professionals Educators' Association, EAHPEA. (2013). Nairobi. Retrieved from https://sites.google.com/ site/eamededucators / eahpea-front-page/june-2013programme/transforming-health-educators-education-conference-report. Accessed on 2015-06-27

WHO. (1995). Defining and measuring the social accountability of medical schools. 